\title{
What triggers puberty?
}

\author{
Ken K Ong ${ }^{1,2}$
}

'What triggers puberty?' was among the '125 Big Questions' posed in Science magazine's 125 th anniversary edition in July 2005. Since then, researchers have made great progress in understanding the genetic, epigenetic and other biological mechanisms that regulate puberty timing, through studies of patients with rare disorders, in large-scale genetic array studies in normal populations and by welldesigned animal models. ${ }^{1}$ As well as being a topic of scientific fascination, this question is highly pertinent to families affected by rare disorders of puberty and to the larger number of families who present with concerns arising from the wide extremes of its normal age distribution, its secular trends and population patterns.

The paper by Kelly et $a l^{2}$ describes substantial patterning by socioeconomic and ethnic background in the prevalence of early age at menarche (the first menstrual period, a late milestone of puberty in girls). They analysed freely available data from the Millennium Cohort Study, a very large prospective UK birth cohort, enriched for socially disadvantaged groups. The main outcome, mother-reported daughter's menarche at the 11 year study interview (mean 11.2 years), was reported by nearly $10 \%$. This age coincides roughly with the earliest $\sim 5 \%$ of girls by UK and other national puberty references, ${ }^{3}$ and corresponds to an onset of puberty (manifested by breast development) at just over 8 years old. Early menarche was two times more likely in the poorest compared with the richest families, and two to three times more likely in Indian, Pakistani, Bangladeshi and black African families compared with white families.

Social patterning in puberty timing has long been described, but historically this was in the opposite direction to that observed here. Observations of relatively later puberty timing in economically deprived population subgroups have been assumed to reflect childhood undernutrition. It is a long-standing concept that

${ }^{1}$ MRC Epidemiology Unit, Institute of Metabolic Science, University of Cambridge, Cambridge, UK; ${ }^{2}$ Department of Paediatrics, University of Cambridge, Cambridge, UK

Correspondence to Dr Ken K Ong, MRC Epidemiology Unit, Institute of Metabolic Science, University of Cambridge, Cambridge Biomedical Campus Box 285, Cambridge CB2 0QQ, UK; Ken.Ong@mrc-epid.cam.ac.uk puberty onset and reproductive hormone axis activity require an adequate nutritional status and these links are increasingly supported by mechanistic insights from human and animal studies. The reversal in social patterning, from relatively late to relatively early puberty timing in economically deprived groups in more recent studies, might plausibly be assumed to follow the similar reversal seen in the social patterning of childhood obesity with time: from relatively lower to relatively higher risk of obesity in economically deprived subgroups. ${ }^{4}$ Hence, it is surprising that differences in childhood body mass index (BMI) explained so little of the social patterning in early menarche timing in the Millennium Cohort Study.

Kelly et $a l^{2}$ found that childhood emotional and behavioural difficulties explained more of the social patterning in early menarche timing than did childhood BMI. While acute stress may delay puberty, likely in the same way as it inhibits the hypothalamic-pituitary axis and causes secondary amenorrhoea in adults, a history of adversity in early childhood appears to accelerate reproductive outcomes such as timings of puberty and first birth. ${ }^{5}$ Life history theory argues that such a fast reproductive strategy may be an adaptive strategy in terms of reproductive success. However, the mechanisms are unknown. Emotional and behavioural difficulties could potentially influence puberty timing by changing lifestyle behaviours such as physical activity and diet. Alternatively, they may somehow alter the yet unidentified inhibitory

influence on the reproductive axis of higher brain centres, a phenomenon that is manifested in clinical practice by the higher risk of precocious puberty in children with hydrocephalus and other generalised brain white matter disorders.

In combination, the candidate factors explored by Kelly et $a l^{2}$ explained only a minority of the social and ethnic group patterning in menarche timing in the Millennium Cohort Study (table 1). So what other explanations might there be? It is possible that childhood physical activity and diet could influence puberty timing, without changing weight gain and BMI. It is also plausible that early life exposures to endocrine-disrupting chemicals might vary by social and ethnic groups. All of these are possible explanations and should be explored in future studies, although measuring those exposures accurately is challenging in large cohort studies. Could the differences between ethnic groups be due to genetic factors? Unfortunately, the recent progress in identifying genetic determinants of puberty timing has yet been confined to white populations. ${ }^{1}$ Furthermore, for topics where trans-ancestry genomic studies are available, for example, obesity and type 2 diabetes, few genetic factors have yet been found that explain ethnic group differences.

Finally, why do these differences matter? First, it is important that paediatricians are aware of such marked patterns in 'normal' puberty timing. It remains a challenge to produce clinical guidelines that appropriately and fairly consider such factors in our investigational assessment to detect rare disorders among children who present with early puberty. Second, in addition to being a possible cause of anxiety and embarrassment, early ages at onset of puberty and menarche influence a wide range of educational and health

Table 1 ORs for early menarche by income and ethnicity, and the proportions of these elevated risks explained by childhood body mass index (BMI), psychosocial stressors and birth weight

\begin{tabular}{lllll}
\hline & OR* & $\begin{array}{l}\text { Explained by } \\
\text { BMI (\%) }\end{array}$ & $\begin{array}{l}\text { Explained by } \\
\text { stressors (\%) }\end{array}$ & $\begin{array}{l}\text { Explained by BMI, } \\
\text { stressors and } \\
\text { birth weight (\%) }\end{array}$ \\
\hline $\begin{array}{l}\text { Income (vs richest) } \\
\quad \text { Poorest }\end{array}$ & 1.95 & 9 & & 45 \\
$\begin{array}{l}\text { Ethnicity (vs white) } \\
\text { Indian }\end{array}$ & 3.55 & 0 & 0 & 0 \\
Pakistani & $1.43 \dagger$ & 0 & 9 & 0 \\
Bangladeshi & 2.45 & 6 & 0 & 21 \\
$\quad$ Black Caribbean & $1.39 \dagger$ & 49 & 18 & 79 \\
$\quad$ Black African & 2.53 & 42 & 0 & 43 \\
\hline
\end{tabular}

Derived from Kelly et al. ${ }^{2}$

*From Model 1 (includes age, income and ethnicity).

tNon-significant association. 


\section{Editorials}

outcomes. In older adults, a history of relatively early puberty timing is associated with higher risks for obesity, type 2 diabetes, cardiovascular disease and several cancers. In adolescents and young adults, relatively early puberty timing is associated with higher likelihood of risktaking behaviours, such as younger age at first sexual intercourse, younger age at first birth and poorer educational achievements. ${ }^{6}$ Therefore, the finding that girls with early menarche at the age of 11 years are already more likely to come from economically deprived backgrounds and to have greater emotional and behavioural difficulties at the age of 7 years compounds the challenge for those working in child public health and education.
Funding Medical Research Council (grant no Unit Programme MC_UU_12015/2).

Competing interests None.

Provenance and peer review Commissioned; internally peer reviewed.

To cite Ong KK. Arch Dis Child 2017;102:209-210.

Received 15 November 2016

Accepted 20 November 2016

Published Online First 8 December 2016

\section{GLinked}

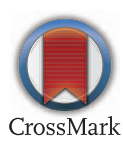

- http://dx.doi.org/10.1136/archdischild-2016-310475

Arch Dis Child 2017;102:209-210.

doi:10.1136/archdischild-2016-312000

\section{REFERENCES}

1 Perry JR, Murray A, Day FR, et al. Molecular insights into the aetiology of female reproductive ageing. Nat Rev Endocrinol 2015;11:725-34.

2 Kelly Y, Zilanawala A, Sacker A, et al. Early puberty in 11-year-old girls: Millennium Cohort Study findings. Arch Dis Child 2017;102:232-7.

3 Mul D, Fredriks AM, van Buuren S, et al. Pubertal development in the Netherlands 1965-1997. Pediatr Res 2001;50:479-86.

4 Shrewsbury V, Wardle J. Socioeconomic status and adiposity in childhood: a systematic review of cross-sectional studies 1990-2005. Obesity (Silver Spring) 2008;16:275-84.

5 Sheppard P, Pearce MS, Sear R. How does childhood socioeconomic hardship affect reproductive strategy? Pathways of development. Am J Hum Biol 2016;28:356-63.

6 Day FR, Helgason H, Chasman Dl, et al. Physical and neurobehavioral determinants of reproductive onset and success. Nat Genet 2016;48:617-23. 